\title{
A NECESSIDADE NO PROCESSO CONSTITUTIVO DAS COMPOSIÇÕES NATURAIS EM ARISTÓTELES
}

\author{
Rodrigo Romão de Carvalho ${ }^{1}$ \\ Universidade de São Paulo (USP) \\ (iD) https://orcid.org/0000-0002-9583-9073 \\ E-mail: romaodc@gmail.com
}

\section{RESUMO:}

Com este artigo, pretendo examinar a maneira pela qual ocorreria a necessidade natural, em seus diversos aspectos, nos distintos processos gerativos composicionais em Aristóteles. Em um caso, a necessidade natural se daria de um modo "sem mais", ou de um modo absoluto, por meio da qual se geram os agregados. Em outro, a necessidade natural se realizaria a partir de um princípio anterior regulativo ou determinante, que Aristóteles denomina de necessidade ex hupoteseos (sob hipótese), com relação aos processos envolvidos na constituição dos corpos homogêneos inanimados e, dos organismos vivos. No entanto, haveria uma diferença essencial relativamente ao acabamento composicional associado, por um lado, aos corpos homogêneos inanimados e, por outro, aos organismos vivos. Enquanto que o acabamento constituinte das composições homogêneas inanimadas se restringiria apenas ao todo composicional e suas propriedades características, o acabamento dos organismos vivos corresponderia ao todo composicional e as suas propriedades características, bem como este acabamento em vista da realização das atividades orgânico-funcionais, ou vitais.

PALAVRAS-CHAVE: Necessidade absoluta; Necessidade ex hupotheseos; Causalidade material; Teleologia; Composições naturais; Aristóteles.

\section{THE NECESSITY IN THE CONSTITUTIVE PROCESS OF NATURAL COMPOSITIONS IN ARISTOTLES}

\begin{abstract}
:
With this paper, I intend to examine the manner in which the natural necessity, in its various aspects, would occur in the different compositional generative processes in Aristotle. In one case, natural necessity would be given in a "simple" or absolute way, through which aggregates are generated. In another, the natural necessity would be based on an earlier regulative or determinant principle, which Aristotle calls ex hypothesis (under hypothesis) necessity, with respect to the processes involved in the constitution of inanimate homogeneous bodies and living organisms. However, there would be an essential difference with respect to the compositional completion associated, on the one hand, with inanimate homogeneous bodies and, on the other, with living organisms. While the constituent completion of inanimate homogeneous compositions would be restricted only to the compositional whole and its characteristic properties, the completion of living organisms would correspond to the compositional whole and its characteristic properties, as well as this finish in view of the accomplishment of the organic-functional activities.
\end{abstract}

KEYWORDS: Absolute necessity; Hypothetical necessity; Material causation; Teleology; Natural compositions; Aristotle.

${ }^{1}$ Doutor em Filosofia pela Universidade de São Paulo (USP), São Paulo - SP, Brasil.

CARVALHO, Rodrigo Romão de. A necessidade no processo constitutivo das composições naturais em Aristóteles. Griot : Revista de Filosofia, Amargosa - BA, v.19, n.1, p.115-126, fevereiro, 2019. 


\section{Introdução}

O conhecimento relativo ao domínio dos seres vivos baseia-se, conforme a concepção aristotélica de natureza, na descrição dos processos através dos quais a forma do animal regula os movimentos absolutamente necessários da matéria elementar, a fim de promover a realização de diversas atividades vitais, dentre as quais a mais fundamental consiste no engendramento constante da compleição orgânica. Aquilo que Aristóteles designa por ananke ex hupotheseos, isto é, necessidade sob hipótese, diz respeito a tais processos: a partir da intervenção de um princípio anterior assumido como hipótese - por exemplo, de um homem (princípio) há de ser gerado (hipótese) outro especificamente idêntico -, o curso espontâneo dos movimentos absolutamente necessários da matéria elementar, decorrente das propriedades essenciais dos elementos, é desviado, de modo a ajustá-lo às circunstâncias nas quais se estabelecem determinadas misturas (por exemplo, carne, ossos, tendões), requisitadas pela composição orgânica. Os elementos, nestas misturas, adquirem, então, propriedades acidentais, as quais são condições necessárias para que o ser vivo seja capaz de realizar as suas atividades características, ou seja, as funções vitais.

Por exemplo, o sangue (haima) se constitui por determinada mistura de elementos, a qual se acrescenta calor (thermotes) por uma influência externa a esta mistura, isto é, pela ação do calor corporal. Para cumprir a sua função no organismo vivo, a saber, servir de alimento às partes do animal ao estar distribuído pelo corpo (cf. As Partes dos Animais, II.3, 650 34-650b4), o sangue deve ser quente na medida em que vem a ser elaborado por um processo de cocção (pepsis). É justamente por meio deste processo de cocção que se acrescenta extrinsecamente a propriedade de ser quente a certa mistura de elementos materiais, que constituem o sangue. No entanto, tais elementos não deixam de preservarem as suas disposições essenciais, de modo que o calor, necessário à função desempenhada pelo sangue, advém-lhes como uma propriedade acidental.

De fato, os elementos materiais que compõe o sangue, quando separados do organismo vivo, passam a assumir outras características, de acordo com suas propriedades intrínsecas. Em uma passagem de As Partes dos Animais, Aristóteles diz:

É claro que o sangue é quente enquanto sua essência de sangue [...], mas com relação ao substrato o sangue não é quente; isto significa que o sangue por um lado é quente, e por outro, não é. [...]. Na medida em que é quente por influência externa, o sangue não é essencialmente quente. $O$ mesmo sucede com respeito ao sólido e ao líquido. Por isso, também, entre as partes que possuem tais qualidades na natureza, umas são quentes e líquidas, mas, ao serem separadas, se solidificam e parecem frias, como o sangue; outras são quentes e têm densidade, como a bílis, e ao separar-se do organismo que as contêm experimentam o contrário: se esfriam e se liquefazem. De fato, enquanto o sangue seca-se mais, a bílis amarela se faz líquida². (cf. As Partes dos Animais, II.3, 649b21-34)

\footnotetext{
${ }^{2}$ Com relação às citações das obras de Aristóteles traduzidas para o português, utilizei a edição "Bekker I", as traduções para o inglês das edições bilíngues da "Loeb Classical Library", as traduções para o espanhol das edições "Gredos", e as traduções para o português de L. Angioni dos Livros I e II da Física e do Livro I das Partes
} 
No organismo vivo, o sangue exibe a propriedade de ser quente e líquido, mas, ao deixar de pertencer ao organismo, torna-se frio e sólido. Algo semelhante acontece com a bílis: na composição do ser vivo, é quente e densa, porém, ao se separar, adquire propriedades contrárias, ou seja, se esfria e se liquefaz. Estas mudanças são explicadas pelo fato de os elementos - ao deixarem de constituir o ser vivo - voltarem a se comportar segundo as suas propriedades intrínsecas (cf. As Partes dos Animais, II.3, 649b28-33, ANGIONI L., 2008, pp. 364-372; Frank A. LEWIS, 1994, pp. 262-267).

Sendo assim, a fim de que o animal seja capaz de executar as funções pelas quais ele vem a ser o que é, e definido enquanto tal, é necessária a emergência de certas propriedades, que só pode ser explicada mediante uma causalidade de tipo teleológica envolvida no processo de constituição do vivente. Isto porque não seria possível que, a partir tão somente das interações espontâneas entre os elementos, sobreviesse os devidos arranjos composicionais, pelos quais se estabelece a complexa rede de estruturas que o organismo comporta: eis no que consiste, de um modo geral, a necessidade ex hupotheseos no exame dos seres vivos.

\section{A necessidade envolvida na geração dos organismos vivos}

A necessidade envolvida no processo gerativo do organismo - em conformidade com a concepção de necessidade "sob hipótese" (ex hupotheseos), a qual estabelece que, se há de ser algo em vista de um acabamento, é necessário que esse algo comporte determinadas condições para a sua realização (cf. Partes dos Animais, I.1, 642 32 -34) - somente ocorre a partir de um princípio causal anterior. Analisando o processo de reprodução sexuada, o princípio causal estipulado como hipótese seria identificado mais precisamente ao calor vital e aos movimentos decorrentes do pneuma contido no sêmen, o qual se apresenta como um fator formal-regulativo que intercede sobre as propriedades essenciais da matéria, de modo a atribuir a estas mesmas outras propriedades sem as quais não haveria à realização das atividades vitais. No ato conceptivo o sperma masculino, contendo o pneuma, transmite ao substrato katamenial feminino (sangue menstrual) - constituído por certa mistura dos quatro elementos - o calor vital e determinados movimentos específicos que, ao interagirem com o katamenia, são capazes de deflagrar as alterações materiais necessárias à formação de um novo indivíduo especificamente idêntico.

Neste sentido, de acordo com M. Furth:

A hipótese de Aristóteles é a de que há no sêmen não a forma mesma, nem alguma porção destinada a se tornar a forma, mas a capacidade de gerar novos indivíduos de tal forma. A natureza desta capacidade é informacional (assim, é frequentemente referida como um logos, uma fórmula). É o logos de uma sequência predeterminada de atividades físicas e químicas formativas ('movimentos' e 'composições') que, dado o katamenia como suporte, será efetuada uma sequência correspondente de mudanças no substrato katamenial, cada mudança pressupondo aquela antes dela, via o postulado mecanismos físico e químico (como causas

dos Animais.

CARVALHO, Rodrigo Romão de. A necessidade no processo constitutivo das composições naturais em 
‘eficientes' ou 'móveis'). (cf. FURTH, M., 1988, p. 117)

De um modo mais ou menos semelhante, M. L. Gill afirma o seguinte:

A fórmula é transmitida à prole através dos movimentos iniciados pelo pai. Uma vez introduzida no material, a fórmula ou o princípio da alma, no interior do novo organismo vivo, assume o processo gerativo e controla os desenvolvimentos subsequentes do animal, regulando o calor e o arrefecimento, de modo a gerar mudanças nos materiais apropriados, nos tempos apropriados, e nos lugares apropriados, produzindo, assim, partes como a carne e o osso. (cf. M. L. GILL, 1997, p. 154)

E ainda, em certa conformidade com M. Furth e M. L. Gill, G. Freudenthal declara:

\begin{abstract}
Os movimentos inerentes ao sangue, sêmen etc. embute o programa para todas as partes distintivas do animal em questão; especificamente, em virtude destes movimentos, o sêmen tem um poder informacional o qual permite transmitir à prole o "programa" inscrito no sangue do progenitor. (cf. G. FREUDENTHAL, 1995, p. 28)
\end{abstract}

O conjunto de variantes proporcionais de calor vital e de movimentos específicos com o qual e pelo qual se preservam os diferentes tipos de partes homogêneas, como o osso ou a carne - as quais por sua vez constituem as diferentes partes não homogêneas, como a mão ou o coração -, em uma condição dinâmica de equilíbrio mútuo no organismo vivo em seu estado maduro, seria transmitido, a modo de potência, ao sêmen masculino na medida em que o fluxo sanguíneo, que alimenta ou nutre as várias partes do ser animado, vem a ser transformado em sperma, por um completo processo de cocção.

No ato conceptivo, este conjunto de variantes proporcionais de calor vital e de movimentos específicos "inscrito" no sperma, a modo de potência, ou assim como, digamos, a modo de um "programa" com capacidade informacional ${ }^{3}$, é retransmitido ao substrato katamenial feminino, de maneira a ativar ou a atualizar a fórmula ou o logos específico do "programa gravado" no sperma. Isto faz com que se instaure o processo epigenético a partir do qual as partes do embrião vêm a ser sucessivamente formados de uma maneira controlada, de acordo com a capacidade informacional efetivamente transmitida. Assim, o conjunto de variantes proporcionais de calor vital e de movimentos específicos contido, em potência ou como um "programa", no sêmen masculino a ser atualizado na ocasião da fecundação, funciona como um princípio formal hipoteticamente necessário sem o qual não haveriam as propriedades materiais adequadas à composição orgânica do vivente.

\title{
A necessidade "sem mais" ou absoluta
}

Em contrapartida, segundo Aristóteles, aqueles que pensavam como

\footnotetext{
3 Gad Freudenthal utiliza a expressão "poder informacional" (informacional power) (cf. FREUDENTHAL, G., 1995, p. 28). No entanto, preferi, seguindo Montgomery Furth (cf. FURTH, M., 1988, p. 117), utilizar a expressão "capacidade informacional", pois penso que o termo "capacidade" está mais próximo do sentido de "potencialidade" (dýnamis).
}

CARVALHO, Rodrigo Romão de. A necessidade no processo constitutivo das composições naturais em Aristóteles. Griot : Revista de Filosofia, Amargosa - BA, v.19, n.1, p.115-126, fevereiro, 2019. 
Empédocles consideravam apenas outro tipo distinto de composição, na qual todos os componentes materiais preservam as suas propriedades essenciais, estabelecendo uma relação de mera justaposição entre as suas partes constituintes, tal como, por exemplo, um agregado de pedras e de ladrilhos que compõem um muro (cf. Geração $e$ Corrupção, II.7, 334 26 e ss.). Este tipo de composições poderia, também, ser atribuída aos agregados elementares que compõem o fogo, a água, a terra, o ar (cf. Metafísica, VII.16, 1040b8-10). Neste caso, a necessidade envolvida no processo de composição não se dá sob hipótese, isto é, a partir de um princípio anterior que determinaria o caráter substancial do todo composicional, mas se dá por meio de uma necessidade "sem mais" (haplos), ou absoluta. Tal necessidade opera na medida em que as séries causais, que resultam na constituição do composto deste tipo, associam-se por uma relação extrínseca de concomitância, através dos movimentos absolutamente necessários das propriedades próprias das partes constituintes, as quais permanecem como são no composto em questão.

No tocante mais especificamente aos compostos orgânicos animados, de acordo com Aristóteles, Empédocles pretendia equivocadamente recorrer tão somente a um conjunto de causas materiais e eficientes, independentemente associadas entre si por uma relação de concomitância, para explicar, por exemplo, a constituição da coluna vertebral no processo de geração de um novo indivíduo:

Empédocles não se pronunciou corretamente ao afirmar que muitos itens
pertencem aos animais porque assim sucedeu concomitantemente no vir a
ser; como, por exemplo, ter a espinha de tal e tal qualidade porque, ao se
retorcer [sc. o corpo], sucedeu-lhe concomitantemente quebrar-se - ele não
reconheceu, primeiramente, que é preciso que o esperma constituidor
esteja já disposto no começo com uma capacidade de tal e tal tipo e, em
seguida, que o produtor se apresente como anterior não apenas por
definição, mas também no tempo: pois é um homem que gera um homem,
de modo que é porque aquele homem é de tal e tal qualidade que o vir a ser
sucede assim de tal modo para este outro. (cf. As partes dos Animais, I.1,
640a19-26)

Segundo Empédocles, ao ver de Aristóteles, seria então suficiente explicar, por exemplo, a formação da espinha dorsal unicamente pelos movimentos absolutamente necessários da matéria que ocorrem espontaneamente. É pela razão da coluna (ákantha) ser constituída por certo tipo de material, acrescentado ao fato de o embrião, casualmente, contorcer-se muitas vezes, que ela apresentaria certas características, ou seja, que ela se apresentaria como um conjunto de vértebras articuladas. Portanto, a função exercida pela espinha no animal como um todo seria devida a uma mera conseqüência dos movimentos espontâneos das disposições dos elementos materiais ${ }^{4}$.

Entretanto, Aristóteles considera que, apesar de necessário certo conjunto de causas materiais e eficientes, esse conjunto não é suficiente, por si só, para engendrar

\footnotetext{
${ }^{4}$ Como Sarah Waterlow observou: "Empédocles e os outros physikoi são retratados por Aristóteles como sustentando que organismos e suas partes orgânicas complexas surgiram por meio de séries de processos causais independentes, envolvendo distintos fatores materiais que se comportam e sofrem transformações pela necessidade de suas próprias naturezas [...], e que simplesmente acontecem ocorrer juntos, uma vez que um ocorre porque um dos outros também, ou através de uma mesma causa" (cf. WATERLOW, S., 1982, p. 76).
}

CARVALHO, Rodrigo Romão de. A necessidade no processo constitutivo das composições naturais em Aristóteles. Griot : Revista de Filosofia, Amargosa - BA, v.19, n.1, p.115-126, fevereiro, 2019. 
as partes do organismo vivo. Antes, é preciso lançar mão de causas formais, as quais conduzem o complexo de causas materiais e eficientes, de modo a estabelecer entre elas uma articulação de interdependência, a fim de promover as propriedades e as disposições composicionais capazes de possibilitar, ao animal, o exercício efetivo de suas funções vitais.

\title{
A necessidade envolvida na geração dos corpos homogêneos inanimados
}

Agora, penso que, mesmo com relação aos compostos homogêneos inanimados, a necessidade estritamente associada à causalidade material já não ocorreria sem mais. Tal necessidade seria envolvida por uma causalidade de tipo formal, ligada à necessidade hipotética: o calor e o frio, enquanto potencialidades ativas, atuam como princípio causal eficiente sobre as propriedades dos componentes materiais através de suas "operações próprias" (ergasían autôn) (cf. Meteorológicos, IV.8, 384b24-26) ${ }^{5}$, de modo a determinar o caráter formal de dada mistura homogênea. Este caráter formal corresponderia a certo grau de umidade e de sequidade que delimita, enquanto potencialidade passiva, as propriedades essenciais de natureza qualitativa do composto como um todo (cf. Meteorológicos, IV.1, 378b2125 ; IV.5, 382 27-382b1; IV.8, 385a $4-8)$.

O princípio formal, que corresponde neste caso ao calor e ao frio natural, atuaria de uma maneira regular e determinada na geração das várias, mas limitadas, composições homogêneas inanimadas, na medida em que há um equilíbrio entre os diversos fatores variantes que operam na natureza de um modo geral. Este equilíbrio foi bem sintetizado por M. Cooper:

\begin{abstract}
Nosso mundo é um sistema de auto-manutenção, com uma tendência embutida a preservar, fundamentalmente, uma mesma distribuição de ar, terra e água; e um mesmo equilíbrio populacional de animais e plantas, em conformidade ao seu próprio tempo. A variação sazonal de períodos quentes e frios, de úmidos e secos, parece fazer com que não ocorra, de uma maneira permanente, um distúrbio na ecologia. (cf. J. M. COOPER, 1987, p. 247)
\end{abstract}

A proporção constante entre os vários elementos e fatores que compõem o meio ambiente como um todo, contribuiria, portanto, para a "auto-manutenção" do equilíbrio natural, que faria com que o calor e o frio atuassem como princípio formal envolvido nos processos de geração dos corpos homogêneos inanimados. Mas, ainda assim, no caso do processo gerativo dos corpos homogêneos inanimados, o princípio formal atuaria de uma maneira menos determinada com relação ao processo gerativo dos compostos orgânicos animados. No primeiro caso, há a dependência de fatores formais externos e, por isto, não tão determinados, aos processos gerativos dos compostos homogêneos inanimados, apesar da regularidade dos fatores envolvidos no conjunto de eventos implicados em um equilíbrio natural do meio ambiente. Já no segundo caso, os fatores formais são internos aos processos gerativos dos

\footnotetext{
${ }^{5}$ Em Geração e Corrupção (II.2, 329b24-30), Aristóteles declara que o quente é capaz de associar coisas do mesmo gênero, pois, por meio dele, destroem-se coisas estranhas ou contrárias (tà allótria), e o frio, capaz de associar tanto coisas do mesmo gênero, quanto coisas distintas (tà mè homóphila).
}

CARVALHO, Rodrigo Romão de. A necessidade no processo constitutivo das composições naturais em Aristóteles. Griot : Revista de Filosofia, Amargosa - BA, v.19, n.1, p.115-126, fevereiro, 2019. 
organismos vivos, na medida em que esses fatores dependem, de um modo geral, da função reprodutiva inerente à natureza própria dos viventes, e, de um modo particular, do pneuma - contendo o calor vital e certos movimentos específicoformativos constantemente produzido pelo coração ${ }^{6}$, de modo garantir, assim, um maior grau de determinação aos processos em questão.

No entanto, apesar de a constituição homogênea dos corpos inanimados como, por exemplo, o bronze e a prata, e a constituição orgânica, isto é, as plantas e os animais, envolverem um fator formal constitutivo, de modo que o todo composicional apresenta certas propriedades distintas das partes (tomadas em si e por si mesmas) que as constituem, penso que o acabamento (tò télos), em vista do qual são necessárias certas condições causais se dá de uma maneira diversa: para que se dê o acabamento composicional (i) dos corpos homogêneos inanimados e (ii) dos organismos vivos, requer-se certa matéria com tais e tais propriedades (cf. Partes dos Animais, I.1, 639b23-27), mas, no primeiro caso (i), o télos, ou o "em vista de quê" (tò hoû héneka), se restringe à consumação do processo constitutivo relativamente aos primeiros estágios, enquanto que, no segundo caso (ii), diz respeito, além disso, à efetivação do processo orgânico-composicional como pré-requisito indispensável para à realização das funções, ou das atividades, vitais ${ }^{7}$.

Através de um processo de cocção, sob efeito do calor, certa combinação de elementos sofre uma transformação na qual o quente e o frio atuam como princípios causais de tipo formal. Na medida em que tal combinação é esquentada e, depois, esfriada, tais princípios fazem com que se atinja certo termo médio entre o quente e o frio. Este termo médio irá demarcar o grau intermediário de umidade e de sequidade - tidos como princípios de tipo material -, que caracterizará o logos, ou a natureza, da composição homogênea em formação (cf. Geração e Corrupção, II.7, 334b24-30), consoante as qualidades próprias que a determinam enquanto considerada, sic et simpliciter, composição homogênea, como, por exemplo, certa maciez, certa dureza, certa viscosidade etc. Por conseguinte, a partir de certa combinação ou de certo agregado de elementos surge um todo unificado e organizado, cujo acabamento por si só irá delimitar o télos a este tipo de composição relacionado.

\section{A distinção dos processos necessários das composições homogêneo-inanimadas e orgânico-animadas}

De um modo geral, a consideração relativa ao processo de toda e qualquer composição homogênea, seja referente à formação de uma composição animada (carne, osso, tendão etc.) ou de uma composição inanimada (ferro, bronze, prata

\footnotetext{
${ }^{6}$ O pneuma seria constantemente produzido pelo coração nos animais sanguíneos, e pelo análogo ao coração nos animais não sanguíneos. No caso das plantas, o pneuma seria internalizado pela raiz, ao absorver à água (contendo o pneuma) que há na terra (cf. Partes dos Animais, II.3, 650²0-23; Geração dos Animais, III.11, $\left.762^{\mathrm{a}} 18-20\right)$.

${ }^{7}$ Sobre a ideia de que haveria, por um lado, um acabamento ou télos natural ligado à consumação da formação composicional em relação aos primeiros estágios e, por outro, um télos natural ligado à realização das funções ou atividades vitais, mas sem referência a uma análise comparativa entre os processos constitutivos dos corpos homogêneos inanimados e dos organismos vivos, ver: KULLMAN, W., 1985, p. 170.
}

CARVALHO, Rodrigo Romão de. A necessidade no processo constitutivo das composições naturais em Aristóteles. Griot : Revista de Filosofia, Amargosa - BA, v.19, n.1, p.115-126, fevereiro, 2019. 
etc.), segue, fundamentalmente, uma mesma linha de raciocínio, ou uma mesma descrição explanatória. A composição homogênea inanimada e a composição homogênea animada ${ }^{8}$ são geradas em função de uma atividade de cocção, na qual em ambas a matéria, isto é, a mistura de certa proporção de elementos, vem a ser dominada ou informada pelas potencialidades ativas (o calor e o frio) (cf. G. FREUDENTHAL, 1995, p. 43), que se apresentam como uma causalidade de tipo formal, de acordo com o princípio da necessidade hipotética.

No entanto, diferentemente das composições homogêneas inanimadas que dependem do calor do Sol, do fogo, para a realização do processo de cocção, as composições homogêneas animadas dependem de outro tipo de calor, a saber, do calor vital ou anímico. Além do calor em si, o calor vital é caracterizado pela condição de estar imbuído de certos movimentos informacionais, os quais desempenham um papel determinante na condução formativa das partes não homogêneas, que constituem o organismo vivo como um todo.

Através do calor, as partes homogêneas animadas vêm a ser geradas por meio de um processo de cocção, tal como os compostos homogêneos inanimados, fazendo com que adquiram certas propriedades essenciais. Entretanto, no caso das composições homogêneas do organismo vivo, elas, sob o efeito de determinados movimentos formativos e específicos, se arranjam de uma maneira complexa e ordenada, de modo a comporem em uma relação intrínseca de interdependência as partes não homogêneas. Estas, por sua vez, passam a adquirir no organismo vivo outras propriedades essenciais, tais como, por exemplo, as propriedades funcionais de pegar e de apertar da mão:

\begin{abstract}
As partes homogêneas, pois, têm recebido respectivamente tais propriedades (uma é macia, outra dura; uma úmida, outra seca; uma viscosa, outra quebradiça), enquanto as partes não homogêneas se apresentam segundo muitas propriedades combinadas entre si; uma propriedade serve à mão para apertar, outra para pegar. (cf. As Partes dos Animais, II.1, 646b19-25)
\end{abstract}

O acabamento ou o télos das partes não homogêneas na compleição orgânica passa a assumir, então, como propriedades essenciais, não mais aquelas meramente de caráter qualitativas que determinam a natureza das composições homogêneas, mas também outras propriedades, agora, de ordem orgânico-funcionais. É necessário que a mão - uma parte não homogênea utilizada como exemplo na passagem supracitada - seja constituída por determinados componentes materiais específicos, tais como a carne a qual manifesta a propriedade de ter certa maciez, ou o osso, o qual manifesta a propriedade de ter certa dureza, a fim de que ela possa apresentar as propriedades que a definem como tal, a saber, as propriedades orgânico-funcionais de pegar e de apertar.

Isto posto, penso que, com relação à distinção entre o acabamento ou o télos característico, por um lado, (i) das composições homogêneas inanimadas e, por outro, (ii) das composições dos organismos vivos, em conformidade com a concepção

\footnotetext{
${ }^{8}$ Composição homogênea animada tomada, meramente, como composição homogênea, sem se levar em conta a sua intrínseca e essencial relação com as composições não homogêneas do organismo vivo, e a constituição orgânica do vivente como um todo.
}

CARVALHO, Rodrigo Romão de. A necessidade no processo constitutivo das composições naturais em Aristóteles. Griot : Revista de Filosofia, Amargosa - BA, v.19, n.1, p.115-126, fevereiro, 2019. 
aristotélica de natureza, poder-se-ia de um modo geral estabelecer certo paralelo entre aquilo que Ernst Mayr discerniu entre (i) processos teleomático se (ii) processos teleonômicos $^{9}$. E. Mayr descreve, respectivamente, os conceitos de processos teleomáticos e de processos teleonômicos do seguinte modo:

\begin{abstract}
Processos teleomáticos na natureza inanimada. Muitos dos movimentos dos objetos inanimados assim como os processos físico-químicos são simples conseqüências das leis naturais. [...] Todos os objetos do mundo físico estão dotados com a capacidade de alterar seu estado e estas alterações seguem as leis naturais. Estão dirigidos a um fim somente em uma forma passiva, automática, são regulados por condições ou forças externas. Posto que o estado final de tais objetos inanimados é alcançado automaticamente, ditas alterações devem ser designadas como teleomáticos. (MAYR, 1998, p.437)

Processos teleonômicos na natureza vivente. Aparentemente, o comportamento dirigido a um fim nos organismos é de uma índole completamente distinta dos processos telomáticos. O comportamento orientado a um fim (no sentido mais amplo desta palavra) se encontra extremamente difundido no mundo orgânico; por exemplo, a maior parte relacionada com a migração, a obtenção do alimento, o cortejo, a ontogenia e todas as fases da reprodução se caracterizam por dita orientação para um fim. Que os processos orientados a um fim ocorram é talvez o traço mais distintivo do mundo dos seres vivos. (MAYR, 1998, p.438)
\end{abstract}

Assim, de acordo com Mayr, os processos de natureza teleonômicos, distintamente dos processos de natureza teleomáticos, exibem uma condição de caráter dinâmica no tocante ao acabamento ou ao télos, em relação aos quais tais processos vêm a ser conduzidos nas operações formativas e conservativas das composições orgânico-vitais. Esta condição de caráter dinâmica seria uma marca distintiva do mundo vivo, relativamente ao mundo dos seres ou das substâncias inanimadas. O télos, neste caso, apresenta-se como um acabamento direcionado a certa(s) finalidade(s). Por outro lado, os processos ditos teleomáticos exibem uma condição de caráter estática. O télos, nesta situação, coincide, sem mais, com o próprio acabamento em função do qual os processos teleomáticos realizam a formação dos objetos inanimados, dependendo de circunstâncias externas para serem conservados como tais.

\title{
Considerações finais
}

Em consonância com a teoria natural de Aristóteles, os processos teleomáticos concebidos por Mayr, grosso modo, poderiam ser entendidos na medida em que, no

\footnotetext{
9 Como o próprio Mayr aponta, Aristóteles já teria se valido, de certa maneira, do conceito de processos teleonômicos: "A existência de programas teleonômicos - forças motoras inamovíveis - é uma das diferenças mais profundas entre o mundo do vivo e o mundo do inanimado, e Aristóteles é o primeiro que postula tal causalidade" (cf. E. MAYR, 1998, p. 452). No tangente aos processos teleomáticos, não há menção, no artigo em análise, de Aristóteles por parte de E. Mayr. No entanto, levando-se em conta as considerações e questões aqui levantadas, creio que seria possível, também, fazer certa aproximação entre processos teleomáticos e as atividades composicionais concernentes às substâncias homogêneas inanimadas, em conformidade com a concepção aristotélica de natureza.
}

CARVALHO, Rodrigo Romão de. A necessidade no processo constitutivo das composições naturais em Aristóteles. Griot : Revista de Filosofia, Amargosa - BA, v.19, n.1, p.115-126, fevereiro, 2019. 
lugar da ideia de operações físico-químicas regidas por forças da lei natural, fosse substituída a ideia de potencialidades ativas, ou seja, o quente e o frio, atuando na condição de princípios da necessidade ex hupotheseos ${ }^{10}$ sobre as potencialidades passivas, isto é, a umidade e a sequidade da matéria composicional da substância homogênea inanimada. Dado esta atuação das potencialidades ativas sobre as potencialidades passivas, segue-se certo equilíbrio passivo ou, como seria talvez nas palavras de Mayr, automático, do seco e do úmido, em função de determinada proporcionalidade dos componentes elementares, de modo a consumar, por completo, o télos a este processo correspondente.

No entanto, para explicar a formação e a conservação, ou seja, a constituição, do organismo vivo, as potencialidades ativas tais como o quente e o frio, por si só, não seriam suficientes para dar conta de uma explanação satisfatória concernente ao complexo conjunto articulado de partes homogêneas e, a partir delas, o conjunto articulado de partes não homogêneas que perfazem a compleição orgânica do vivente como um todo (cf. S. M. COHEN, 1996, p. 154). Antes, seria preciso lançar mão de algo a mais, um conceito que pudesse, ao mesmo tempo, manter a ideia do processo de cocção ordinário envolvido na produção dos compostos homogêneos de uma maneira geral, e, ainda assim, sustentar a explicação destes compostos de se arranjarem de uma maneira ordenada e complexa a fim de, em última instância, desenvolverem propriedades funcionais.

Ao que parece, a solução veio, seguindo a posição de Freudenthal (cf. 1995, pp.137-144), com o conceito de pneuma. O pneuma é, como vimos anteriormente, um calor determinado, vital, imbuído de certos movimentos específicos e informativos. É aqui que entra a proximidade com o conceito de processos teleonômicos de E. Mayr. O calor, como tal, seja ele vital ou não, é responsável pelo processo de cocção comum a toda atividade de geração dos corpos homogêneos, tanto animada como inanimada. Porém, no tocante às partes homogêneas animadas do organismo vivo, entra em ação um elemento chave, a saber, os movimentos específicos e informativos, co-natural ao calor, designado, "vital", o qual, em função da associação essencial com tais movimentos, é referido de um modo sintético como pneuma.

O pneuma, atuando como necessidade ex hupotheseos, no lugar, simplesmente, do calor e do frio nos casos dos processos que, talvez, E. Mayr poderia considerar como teleomáticos, promoveria a atividade de composição das partes homogêneas animadas na conformação das partes não homogêneas do organismo vivo - e, por conseguinte, da constituição orgânica como um todo - à condição de princípio teleonômico, o qual teria por base a ideia de um comportamento orientado a um fim, de caráter dinâmico. Tal fim ou télos, portanto, não coincidiria com o mero acabamento composicional da substancialidade orgânico-vital, mas tal acabamento em vista das funções ou atividades anímicas.

10 Necessidade a partir de certo princípio anterior, sem o qual não haveria determinado acabamento composicional ulterior.

CARVALHO, Rodrigo Romão de. A necessidade no processo constitutivo das composições naturais em Aristóteles. Griot : Revista de Filosofia, Amargosa - BA, v.19, n.1, p.115-126, fevereiro, 2019. 


\section{Referências}

ANGIONI, L. As Noções Aristotélicas de Substância e Essência. Campinas, Ed. Unicamp, 2008.

ARISTÓTELES. Aristotelis Opera. BEKKER, I. (ed.). Academia Regia Borussica, Vols. I-II, Berlim, 1831.

ARISTÓTELES. The Metaphysics, Books I-IX. Trad.: Hugh Tredennick, London: The Loeb Classical Library, 1947.

ARISTÓTELES. Generation of Animals. Trad.: A. L. Peck, London: The Loeb Classical Library, 1953.

ARISTÓTELES. On Sophistical Refutations; On Coming-to-be and Passing Away; On the Cosmos. Trad.: E. S. Foster, and D. J. Furley, London: The Loeb Classical Library, 1955.

ARISTÓTELES. On the Soul; Parva Naturalia, On Breath. Trad.: de W. S. Hett, London, The Loeb Classical Library, 1957.

ARISTÓTELES. Parts of Animals; Movement of Animals; Progression of Animals. Trad.: A. L. Peck, London: The Loeb Classical Library, 1961.

ARISTÓTELES. Reproduccíon de los Animales. Trad. e notas de E. Sánchez, Madri: Biblioteca Clásica Gredos, 1994.

ARISTÓTELES. Acerca del Cielo; Meteorológicos. Trad. e notas de M. Candel, Madri, Biblioteca Clásica Gredos, 1996.

ARISTÓTELES. Acerca de la Generación y la Corrupción; Tratados Breves de Historia Natural. Trad. e notas de E. La Croce, e A. B. Pajares, Madri: Biblioteca Clásica Gredos, 1998.

ARISTÓTELES. As Partes dos Animais, Livro I. Trad. e comentários de L. Angioni, Cadernos de História e Filosofia da Ciência, 9 (3) (n. especial), 1999.

ARISTÓTELES. Partes de los animales; marcha de los animales; movimiento de los animales. Trad. e notas E. J. Sánchez-Escariche e A. A. Miguel, Madri: Biblioteca Clásica Gredos, 2000.

ARISTÓTELES. Física. Trad. e notas de G. R. de Echandía, Madri: Biblioteca Clásica Gredos, 2002.

ARISTÓTELES. Acerca del Alma. Trad. e notas de T. C. Martínez, Madri: Biblioteca Clásica Gredos, 2003.

ARISTÓTELES. Metafísica. Trad. e notas de T. C. Martínez, Madri: Biblioteca Clásica Gredos, 2006.

ARISTÓTELES. Física I-II. Trad. e comentários de L. Angioni, Campinas: Ed. Unicamp, 2009.

COHEN, S. M. Aristotle on Nature and Incomplete Substance. New York: Cambridge University Press, 1996.

COOPER, J. M. "Hypothetical necessity and natural teleology". A. Gotthelf e Lennox, J. (eds.), Philosophical Issues in Aristotle's Biology. Cambridge: Cambridge University Press, 1987, pp. 243-274.

FREUDENTHAL, Gad. Aristotle's theory of material substance: heat and pneuma, form and soul. Oxford: Clarendon Press, 1995.

FURTH, Montgomery. "Aristotle's biological universe: an overview". A. Gotthelf e Lennox, J. (eds.), Philosophical Issues in Aristotle's Biology. Cambridge: Cambridge 
University Press, 1987, pp. 21-52.

GILL, Mary Louise. Material Necessity and Meteorology IV 12. Aristotelische Biologie: intentionen, methoden, Eegebnisse. Stuttgart: Franz Steiner, 1997, pp. 145161.

KULLMANN, W. "Differents Conceptions of the Final Cause in Aristotle". A. Gotthelf (ed.), Aristotle on Nature and Living Things. Pittsburgh, Bristol: Mathesis publications, 1985, pp.169-175.

LEWIS, Frank A. "Aristotle on the Relation between a Thing and its Matter". T. Scaltsas, D. Charles e M. L. Gill (eds.), Unity, Identity and Explanation in Aristotle's Metaphysics. Oxford: Clarendon Press, 1994, pp. 247-277.

MAYR, Ernst. "Los Múltiples Significados de Teleológico". Trad.: Gaona, A. L., in Historia y explicación en biologia. México: Universidad Nacional Autonóma de México - Fondo de Cultura Económica, 1998, pp.431-461.

WATERLOO, Sarah. Nature, Change and Agency in Aristotle's Physics. Oxford: Clarendon Press, 1982.

Autor(a) para correspondência: Rodrigo Romão de Carvalho, Universidade de São Paulo, Departamento de Filosofia, Av. Prof. Luciano Gualberto, 315, 05508-010, São Paulo - SP, Brasil. romaodc@gmail.com 